La construcción del discurso identitario nacional argentino: la historia de la carne

Diego Luis Forte

DOI: https://doi.org/10.24215/16696581e233

\title{
La construcción del discurso identitario nacional argentino: la historia de la carne
}

\section{The construction of argentina's national identity discourse: the story of meat}

\author{
Diego Luis Forte: dforte@filo.uba.ar \\ https://orcid.org/0000-0002-6548-7492 \\ Facultad de Filosofía y Letras; Universidad de Buenos Aires (Argentina)
}

Resumen

Las representaciones sociales construidas y reproducidas a través de los discursos construyen marcos e historias que pautan y limitan nuestras posibilidades de acción en la vida diaria. La Historia de la Carne (Adams, 1990) es la narrativa que ha regido el discurso sobre la Nación en 
la Argentina desde su fundación. Este marco se ha construido durante doscientos años a través de todos los discursos circulantes en el país.

El presente trabajo adopta como marco teórico el Análisis Crítico del Discurso desde la perspectiva propuesta por la Ecolingüística (Stibbe, 2015). Utilizaremos las herramientas de análisis presentadas por Lakoff $(2004,2010)$ y Kress y van Leeuwen (2006). Nos proponemos analizar la construcción del marco identitario especista a través de discursos verbales y multimodales de diferentes épocas y presentar discursos alternos.

Palabras Clave: discurso, frame, multimodalidad, especismo

\section{Abstract}

Social representations that we build and reproduce through discourses construct frames and stories that limit our possibilities of action in daily life. The Story of Meat (Adams, 1990) is the framework that has governed discourses about National Identity in Argentina since its founding as a nation. This framework has been built through the two hundred years of the Nation's history and involves all circulating discourses in the country.

The present work adopts Critical Discourse Analysis as main theoretical from the perspective proposed by Ecolinguistics (Stibbe, 2015). We will use the analysis tools proposed by Lakoff $(2004,2010)$ and Kress and van Leeuwen (2006). Our aim is to analyze the construction of the speciesist identity frame through verbal and multimodal speeches from different eras and present alternative discourses.

Keywords: discourse, frame, multimodality, speciesism

\section{Lenguaje y realidad}

En el curso de nuestra vida como humanos adjudicamos sentido a todo lo que nos rodea. Pero no solo etiquetamos y clasificamos el mundo a nuestro alrededor sino que también lo construimos: el lenguaje no es solo un dispositivo para describir el mundo sino también una herramienta de construcción (Whorf, 1957: 246). Creamos representaciones sociales a través del discurso que contienen una valoración tanto personal como colectiva, y al reproducirlas, estamos reproduciendo significados de construcción colectiva. 


\section{Framing y construcción de significado}

Las perspectivas cognitivas sobre el discurso plantean que los significados se almacenan en la mente de acuerdo con diversos ejes, que en ciertos casos pueden coincidir con campos semánticos: todo lo relacionado al ámbito médico-hospitalario estará más o menos cerca y conectado y lo mismo sucederá con lo político, lo educacional, etc. De esta forma estarán disponibles de forma más o menos rápida para su utilización cuando se requieran. Esto es lo que se denomina marco o frame. La mención en el discurso de alguno de estos ítems activa el marco completo. Lakoff lo describe de la siguiente forma:

One of the major results in the cognitive and brain sciences is that we think in terms of typically unconscious structures called "frames" (sometimes "schemas"). Frames include semantic roles, relations between roles, and relations to other frames. A hospital frame, for example, includes the roles: Doctor, Nurse, Patient, Visitor, Receptionist, Operating Room, Recovery Room, Scalpel, etc. Among the relations are specifications of what happens in a hospital, e.g., Doctors operate on Patients in Operating Rooms with Scalpels. These structures are physically realized in neural circuits in the brain. All of our knowledge makes use of frames, and every word is defined through the frames it neurally activates. All thinking and talking involves "framing." And since frames come in systems, a single word typically activates not only its defining frame, but also much of the system its defining frame is in (Lakoff, 2010: 71-72). (1)

Cuando apelamos a determinadas representaciones estamos activando marcos particulares en la mente de nuestros interlocutores. Así, es posible pensar crisis sociales o económicas en términos de tormentas o tiempo atmosférico; asociando nuestro discurso con otros no necesariamente conectados a priori.

Los marcos discursivos son estructuras formadas por significado compartido socialmente y remiten un pasado común. No solo funcionan sincrónicamente sino que pueden constituirse como narraciones que implican una inserción en una historia: dentro de la cultura europea occidental la Historia del Héroe se ha constituido como la narración fundacional en todas las naciones modernas. A través de esta historia, el significado de héroe (Hadas, 1948: 408) se conecta con el de batalla, enemigo, conflicto, victoria, e incluso con honor, lealtad, etc. De esta forma, los marcos nos relacionan también a partir de narraciones que construyen una visión del mundo consistente y se constituyen en historias que vivimos diariamente. Cuando utilizamos la categoría recursos naturales estamos considerando que la naturaleza es algo que está disponible para nuestra supervivencia en lugar de considerar que somos parte de ella. De esta forma, al considerar a la naturaleza como recurso, el lenguaje construye un marco que limita 
nuestras posibilidades de acción (Stibbe, 2015: 8). Si pensamos en la historia del héroe los roles sociales están también asignados y así, enfrentamos cada conflicto en nuestras vidas como si fuera una gesta épica: desde la liberación del continente hasta el arreglo de una canilla. Cada una de estas historias/marcos funciona como un todo cohesivo integrado: fuera de ellas el significado se considera marginal, subestándar. Midgley lo define de la siguiente manera:

\begin{abstract}
They are imaginative patterns, networks of powerful symbols that suggest particular ways of interpreting the world. They shape its meaning. For instance, machine imagery, which began to pervade our thought in the seventeenth century, is still potent today. We still often tend to see ourselves, and the living things around us, as pieces of clockwork: items of a kind that we ourselves could make, and might decide to remake if it suits us better. Hence the confident language of 'genetic engineering' and 'the building-blocks of life'. (Midgley, 2003: 1). (2)
\end{abstract}

\title{
Semiótica social y análisis crítico del discurso
}

En tanto disciplinas aledañas, la Semiótica Social y el ACD operan en estrecha colaboración. El análisis crítico del discurso pretende desarmar la construcción discursiva de los prejuicios, de posiciones hegemónicas para demostrar que estas posiciones son naturalizadas a través del lenguaje pero que no son naturales.

El análisis crítico del discurso es un tipo de investigación analítica sobre el discurso que estudia primariamente el modo en que el abuso del poder social, el dominio y la desigualdad son practicados, reproducidos, y ocasionalmente combatidos, por los textos y el habla en el contexto social y político. El análisis crítico del discurso, con tan peculiar investigación, toma explícitamente partido, y espera contribuir de manera efectiva a la resistencia contra la desigualdad social (van Dijk, 1999: 23).

Pero no todo el significado es construido a través del sistema lingüístico, aunque sí sea clasificado e interpretado a través de éste. Es aquí donde entra la Semiótica Social. El significado se construye a través de diferentes sistemas o modos: visual, auditivo, etc. Las imágenes y el sonido transmiten información que posibilita la construcción de representaciones (Kress \& van Leeuwen, 2005: 17). Las imágenes también transmiten significado y, al igual que el discurso lingüístico, están compuestas por elementos atados a la experiencia de la vida en sociedad, por lo que también construyen marcos. 


\section{Ecolingüística y la construcción social de los animales}

En primer lugar debe mencionarse que los animales no humanos son descriptos y clasificados a través del lenguaje pero no participan ellos mismos en la construcción discursiva que los construye.

The role of language in structuring power relations, in particular, has come under close scrutiny (...) Most of this work on language and power focuses on the role of discourse in oppression and exploitation. For example, the journal Discourse and Society is dedicated to "power, dominance and inequality, and to the role of discourse in their legitimization and reproduction in society, for instance in the domains of gender, race, ethnicity, class or world religion". However, with rare exceptions, the role of discourse in the domination by humans of other species has been almost entirely neglected in the field of critical discourse analysis. Power is talked about as if it is a relation between people only; for example, Fairclough (1992) describes the way that "language contributes to the domination of some people by others" ... Because of the neo-Marxist roots of critical discourse analysis, analysis focuses on hegemony, where oppression of a group is carried out ideologically rather than coercively, through the manufacture of consent. In the case of animals, the power is coercive, carried out by a small number of people involved in organizations that farm and use animals. The animals do not consent to their treatment because of an uncritical acceptance of the ideology of the oppressor, and they cannot be empowered to resist the discourses that oppress them (Stibbe, 2001: 146). (3)

La Ecolingüística como disciplina, tiene un objetivo similar al presentado por el ACD: desarmar las historias o marcos que rigen nuestras vidas y que pueden ser destructivos para con otras formas de vida.

\section{La historia de la carne}

En su libro The Sexual Politics of Meat (1990) Carol Adams menciona el libro de Alice B. Toklas para referirse a lo que ella denomina la historia de la carne.

The story of meat follows the narrative structure of storytelling. Alice B. Toklas implies this in her cookbook when, in a chapter entitled "Murder in the Kitchen," she uses the style of a detective story to describe killing and cooking animals. Through recipes she provides the appropriate conclusion to the animals' death according to the texts of meat; the animal becomes delectable, edible... Meat eating is story applied to animals, it gives meaning to animals' existence... The story of meat follows 
a sacred typology: the birth of a god, the dismemberment of the god's body, and the god's resurrection. This sacred story paves the way for a mundane enaction of the meaning of dismemberment and resurrection—achieved through consumption of meat (Adams, 2017: 76). (4)

De acuerdo con la descripción de Adams, la historia de la carne funciona como marco de significado que otorga un rol particular a cada participante, definiendo sus posibilidades y creando marcos de interpretación especistas, asignando referentes específicos a animales no humanos, convirtiéndolos en alimentos, entretenimiento, ropa o material de investigación. Nuestro objetivo en este trabajo es presentar algunos elementos que han construido un marco especista ligado a la carne y la narrativa sobre la identidad nacional argentina que, siguiendo a Adams vamos a denominar La Historia de la Carne.

\section{La historia que viven los argentinos}

La historia de la Carne activa y enlaza significados como asado, tradición, amistad, relajación, reunión, e incluso fiesta, familia y masculinidad heterosexual hegemónica. La relación entre estos signos y el discurso sobre la identidad nacional se evidencia en numerosas prácticas sociales (Navarro, 2016: 126). Este marco fue construido junto con la identidad nacional, es parte de esta y se manifiesta en todos los discursos nacionales: literatura, discurso político y gubernamental, periódicos y medios de comunicación, música, etc. Desde las primeras descripciones de los viajeros europeos hasta el mito de "la mejor carne del mundo", el campo y el ganado bovino han desempeñado un papel importantísimo en la identidad nacional. Primero como herramienta para el poblamiento y luego como emblema, el significado vaca es parte de procesos en los que participan todos los argentinos y que pautan sus posibilidades de acción en la vida diaria.

El punto de partida es el inicio de la Nación: civilización y barbarie: para civilizar la barbarie hay que poblar el desierto; y para poblar el desierto hay que convertir las áridas y solitarias tierras, pobladas por los salvajes indios, en parcelas para ganado. El momento en que los hacendados se adueñan de la tierra y la utilizan para la cría de ganado coincide con el momento en el que el desierto se convierte en fértiles campos y las vacas en la riqueza de la nación.

Entonces debemos comenzar por preguntarnos cómo se construyó la idea de desierto/barbarie en la República Argentina. 


\section{Los viajeros ingleses}

La representación del territorio argentino comienza con una visión europea. Casi una década después de proclamar su independencia de la corona española, el país comenzó a recibir diferentes delegaciones inglesas, las cuales incluían ingenieros, botánicos, comerciantes y diferentes tipos de profesionales cuyo objetivo era examinar las posibilidades comerciales del país. Estos contingentes fueron atraídos por una intensa campaña de propaganda organizada estratégicamente por las autoridades del Río de la Plata para tentar a los capitales extranjeros, principalmente europeos (Prieto, 1996: 29). Muchas de estas expediciones se describieron en libros de historias de viajes al estilo Alexander von Humboldt (1996: 30) y tenían el propósito aparente, característico de este tipo de narrativas, de desarrollar "un tratamiento estético de los temas de la naturaleza".

Los libros publicados por John Miers (Travels in Chile and La Plata, London, Baldwin, Cradock and Joy, 1826), Joseph Andrews (Journey from Buenos Aires, through the provinces of Cordova, Tucuman, and Salta, to Potosí, London, John Murray, 1827) y John A.B. Beaumont (Travels in Buenos Aires, and the Adjacent Provinces of The River of La Plata with observations, London, James Ridgway, 1828) son solo algunos de los más de diez títulos que atestiguan este interés por la descripción detallada y la evaluación de la experiencia sudamericana de los autores. Fueron escritos para una audiencia europea y sus descripciones ayudaron a crear una imagen del país de acuerdo con una selección muy específica de los elementos descriptos. Estas pautas coinciden, como veremos, con los empleados de escritores que, como Alberdi, Echeverría y Sarmiento, pusieron la piedra angular, no solo para la literatura nacional argentina, sino también para el discurso de identidad nacional (Prieto, 1996: 12-13).

John Miers, Travels in Chile and La Plata

Publicado en Londres en 1826 el libro describe un viaje de reconocimiento realizado en 1819, partiendo desde la ciudad de Buenos Aires, cruzando la extensa llanura y los Andes para llegar a Chile. Miers era experto en minería y su objetivo era evaluar las posibilidades de explotación para esa industria en Chile. Si bien el territorio argentino carecía de interés para su viaje, Miers incluye en sus notas algunas breves referencias, guiadas por el criterio estético europeo utilitario de su generación: no le interesa el nuevo paisaje, todo lo que se aleja de la cultura 
europea de su época es inútil y no tiene valor (Prieto, 1996: 30). En su visión la pampa luce como an endless bowling lane (Miers, 1826: 13).

\section{Alexander Caldcleugh, Travels in South America during the Years 1819-20-21}

Este libro fue publicado en Londres en 1825 en un intento de mostrar Argentina, Brasil y Chile como potenciales centros de inversión. La información brindada sobre Argentina incluye reportes de historia, formas de gobierno, sistema de comercio y vías de comunicación con recursos naturales (Prieto, 1996: 31). Travels in South America se concentra en la descripción de prácticas políticas y económicas, como así también el rol de los caudillos locales en disputas internas, conectando el concepto de desierto con el de desorden social (1996: 32). Respecto de la Pampa Caldcleugh menciona "... the journey is uninteresting, being over a continued plain with little wood or water, and with no boundary but the horizon..." (1825: 240). Tal como en la visión de Miers, para Caldcleugh, el único valor de la naturaleza reside en sus recursos.

Francis Bond Head, Rough Notes Taken During Some Rapid Journeys across the Pampas and Among the Andes

Los escritos del capitán Francis Bond Head son de particular interés para la literatura argentina. Bond Head arribó al Río de la Plata en 1825 con el encargo de informar sobre las posibilidades de explotación de las minas de oro y plata, primero en Argentina y luego en Chile (1996: 37). Rough Notes... publicado al año siguiente, en 1826. La misión había fracasado y el objetivo del libro parecía ser justificar el fracaso buscando algún beneficio económico en el campo literario. En este sentido, el libro manifiesta un claro objetivo estético, desarrollando la evolución de los pensamientos del autor y redescubriendo las bellezas de la llanura. Pero no es tanto un desarrollo informativo sobre el medio ambiente como una reflexión filosófica sobre la vida y la libertad. Bond Head presenta una visión que opone sociedad y naturaleza: el hombre se perfecciona en la sociedad, en un estado natural es un salvaje incapaz de progresar. En su relación con el ambiente natural que habita, el gaucho representa al hombre que aún no está contaminado por los males de la civilización.

Sus descripciones de la ciudad de Buenos Aires mantienen una diferencia entre las ciudades europeas y las del Nuevo Continente, dejando clara su perspectiva sobre las provincias del Río de la Plata: 
Some of the principal families at Buenos Aires furnish their rooms in a very expensive, but comfortless manner: they put down upon the brick floor a brilliant Brussels carpet, hang a lustre from the rafters, and place against the damp wall, which they whitewash, a number of tawdry North American chairs. They get an English piano-forte, and some marble vases, but they have no idea of grouping their furniture into a comfortable form: the ladies sit with their backs against the walls without any apparent means of employing themselves; and when a stranger calls upon them, he is much surprised to find that they have the uncourteous custom of never rising from their chairs. (Bond Head, 1826: 30-31).

y luego,

The society of Buenos Aires is composed of English and French merchants, with a German or two. The foreign merchants are generally the agents of European houses; and as the customs of the Spanish South Americans, their food, and the hours at which they eat it, are different from those of the English and French, there does not appear to be much communication between them. At Buenos Aires the men and women are rarely seen walking together; at the theatre they are completely separated; and it is cheerless to see all the ladies sitting together in the boxes, while the men are in the pit,--slaves, common sailors, soldiers, and merchants, all members of the same republic (1826: 31$)$.

La falta de civilización parece originarse, según Bond Head, en la desorganización. En cualquier caso, el manuscrito se cierra con una advertencia para sus compatriotas sobre los riesgos de emigrar a un país como Argentina, cuya atención debe decidirse sobre cualquier tipo de inversión en un medio que parece ignorar cualquier regla.

\section{Generación del 37}

Su trabajo cubrió diferentes géneros pero en todos ellos hubo un tema recurrente que los unió: la nación. Esta era una pregunta típicamente romántica que en un nuevo país como Argentina se intensificó por el vacío que planteaba el desierto. El estudio de "lo Nacional", proclamado como un objetivo principal por Alberdi en su discurso para el Salón Literario de 1837, se convirtió en el leitmotiv de toda una generación literaria.

\section{Juan Bautista Alberdi}

Su obra Bases y puntos de partida para la organización política de la República Argentina, fue la guía no oficial de los representantes nacionales que redactaron el borrador de la constitución 
argentina; sentó las bases del discurso nacional y estableció oficialmente la oposición civilización / barbarie como punto de partida. Con su frase icónica, contenida en Bases: "gobernar es poblar", Alberdi se refiere a la idea de importar civilización, ocupando los espacios vacíos del vasto territorio. Siguiendo esta frase, Alberdi argumenta que necesitamos constituciones; necesitamos una política de creación, de población, de conquista sobre la soledad y el desierto. El crecimiento económico parece ser la mejor manera de consolidar el perfil de una nueva nación, cuyo enemigo ya no es la metrópoli, sino lo que la Generación de los 37 designó con el nombre de desierto. Esta frase no refiere tanto al poblamiento del territorio como a la introducción de un agente moralizador en el desierto. En este sentido se habla de "trasplantar" hábitos, costumbres y prácticas mediante una política agresiva de atracción de la inmigración europea, especialmente de origen nórdico y anglosajón:

¿Queremos plantar y aclimatar en América la libertad inglesa, la cultura francesa, la laboriosidad del hombre de Europa y de Estados Unidos? Traigamos pedazos vivos de ellas en las costumbres de sus habitantes y radiquémoslas aquí. ¿Queremos que los hábitos de orden, de disciplina y de industria prevalezcan en nuestra América? Llenémosla de gente que posea hondamente esos hábitos. Ellos son comunicativos; al lado del industrial europeo pronto se forma el industrial americano. La planta de la civilización no se propaga de semilla. Es como la viña, prende de gajo (1852: 97).

\section{Esteban Echeverría}

En La cautiva, el dualismo civilización-barbarie se declara en el desierto como personaje central. La trama narra cómo Brián y María, esposo y esposa, son capturados por indios en la frontera. Luchan por escapar y volver a la ciudad. Después de varios problemas, María rescata a Brián, pero es demasiado débil y muere. María muere más tarde, cuando descubre que su hijo fue asesinado por los indios. La barbarie de los indios se presenta como un elemento del paisaje, de la naturaleza. $\mathrm{Y}$ el resultado fusiona a los héroes, que representan el mundo civilizado, con la naturaleza, la pampa. Sin embargo, el objeto de libertad y vida buscado por los protagonistas no se logra. María y Brián sucumben a esta naturaleza que tiene los gérmenes de la barbarie. Esta oposición principal, la civilización-barbarie, es el eje de otras dicotomías, como la naturaleza amorosa y la muerte amorosa. Brián, un guerrero idealizado de los hechos de la independencia, es derrotado por las fuerzas bárbaras del desierto y de los indios. Superar obstáculos como el indio y el desierto es parte de un programa para sentar las bases de un nuevo país y su organización nacional (recordar que "gobernar es poblar"). Esta es la declaración original de la Generación del 37. 
La otra obra fundacional de Echeverría es el relato El matadero. En esta historia describe una escena más virulenta: un ciudadano joven y refinado de Buenos Aires es asesinado por un matarife, un trabajador de un matadero en el campo. La historia presenta dos mundos opuestos: el de los matarifes y otros personajes relacionados con el trabajo en el matadero, que simboliza al federalismo político del campo, por un lado; y el refinado e indignado mundo cuyo arquetipo es el joven unitario, representante político de la ciudad, por el otro. Esta lucha presenta una batalla política que continúa representando la civilización de la ciudad versus la barbarie del campo.

Domingo Faustino Sarmiento

Facundo se centra en la figura y la historia del caudillo riojano Facundo Quiroga como una excusa para oponer Buenos Aires (una ciudad civilizada a la manera europea) a la barbarie del resto del territorio.

\begin{abstract}
El mal que aqueja a la República Argentina es la extensión: el desierto la rodea por todas partes, y se le insinúa en las entrañas; la soledad, el despoblado sin una habitación humana, son, por lo general, los límites incuestionables entre unas y otras provincias. Allí, la inmensidad por todas partes: inmensa la llanura, inmensos los bosques, inmensos los ríos, el horizonte siempre incierto, siempre confundiéndose con la tierra, entre celajes y vapores tenues, que no dejan, en la lejana perspectiva, señalar el punto en que el mundo acaba y principia el cielo. Al sur y al norte, acéchanla los salvajes, que aguardan las noches de luna para caer, cual enjambres de hienas, sobre los ganados que pacen en los campos y sobre las indefensas poblaciones (1845: 67).
\end{abstract}

La idea expresada en el título "civilización o barbarie" separa no solo a los personajes y las costumbres, sino también paisajes completamente diferentes. La oposición se presenta como una división innata de la población del país que daría origen a la división política: unitaria o federal, civilizada o bárbara, de la ciudad o el campo. Sarmiento sigue los postulados de su generación: la distinción entre civilización y barbarie se basa en las similitudes de Europa y los Estados Unidos con Buenos Aires, mientras que las provincias están asociadas con oriente y se describen como regiones subdesarrolladas. El contraste entre ambos mundos se muestra a través de la figura de Facundo.

Posteriormente, el problema del vacío da lugar al problema de la distribución de la riqueza (una riqueza originada en la explotación del ganado): cuarenta años después de la publicación de Facundo, el desierto se ha convertido en tierras de ganado. Las familias más ricas se han 
hecho cargo y lo han convertido en una gran área de producción de ganado. Ante esta situación, Sarmiento parece cambiar de opinión y señala:

\begin{abstract}
Hace 20 años valía más una libra de manteca que una vaca con ternero. Esa es la síntesis de nuestro espíritu industrial, esa es nuestra desidia y la índole de nuestra actividad nacional (...) [Los ganaderos] no quieren saber nada de derechos, de impuestos a la hacienda. Quieren que el gobierno, quieren que nosotros que no tenemos una vaca, contribuyamos a duplicarles 0 triplicarles su fortuna... A los Anchorena, a los Unzué, a los Pereyra, a los Luros, a los Duggans, a los Cano y los Leloir y a todos los millonarios que pasan su vida mirando cómo paren las vacas. En este estado está la cuestión, y como las cámaras (del Congreso) están también formadas por ganaderos, veremos mañana la canción de siempre, el payar de la guitarra a la sombra del ombú de la Pampa y a la puerta del rancho de paja (1886: 1).
\end{abstract}

El campo es símbolo de atraso; la ciudad, del progreso; por eso es necesario cambiar el paisaje rural, convertir a sus habitantes hacia otro paradigma, hacia otra forma de pensar. Pero para 1886, Sarmiento parece cambiar de opinión en tanto el desierto se ha transformado en tierra ganadera: los ganaderos ya no son más bárbaros salvajes sino barones del ganado en una nación ya establecida.

\title{
Libro de lectura El Argentino
}

Como uno de los Aparatos Ideológicos del Estado (Althusser, 1971: 124), el propósito principal de la escuela es adoctrinar a los ciudadanos para que se conviertan en el ideal nacional. Como práctica social, la educación se convierte en una forma de moldear y limitar el comportamiento individual y colectivo mediante la introducción de una ideología dada en los niños. Por lo tanto, los materiales educativos e instruccionales constituyen canales fundamentales de comunicación; concretan conceptos durante el proceso de enseñanza y aprendizaje. Así, podemos encontrar elementos que vinculan el concepto de Nación con la dicotomía civilización/barbarie. El libro de lectura para escuela primaria El Argentino (1885) presenta la Conquista del Desierto como un evento notable:

El acontecimiento más notable de la época presente, es, sin disputa, la conquista del desierto. Después de trescientos años de combates sin tregua, los salvajes del Sur permanecían ocupando territorios inmensos. La riqueza de los campos consistente en ganados era la presa continua de los indios bárbaros. El asesinato y el incendio señalaban sus pasos constantemente. Sumas cuantiosas se invertían todos los años en la defensa de las fronteras, pero siempre con resultado 
negativo. Si las tribus más próximas se sometían al Gobierno, otras más lejanas abandonaban el fondo de la Pampa y esparciéndose por las poblaciones rurales conducían en grandes tropas los ganados argentinos hasta los territorios del sur de Chile. Todos los medios empleados para detenerlos resultaban ineficaces, y cada año aumentaban las terribles depredaciones. El arduo problema de los indios parecía insoluble; empero un hombre destinado a vengar la civilización de tan largo ultraje apareció en escena. Ese hombre fue el general Roca, que a despecho de las opiniones más conceptuadas puso en práctica un sistema vigoroso contra los salvajes, no para destruirlos, sino para someterlos, y civilizarlos, trayéndolos vencidos a participar de los derechos que gozan todos los argentinos (Pelliza, 1885: 108-109).

Lo que el texto manifiesta es que la campaña fue necesaria, gloriosa y Roca es un héroe nacional. Luego de esta declaración, el libro presenta el apoyo de la industria nacional al desarrollo de la Nación:

Establecida la paz en la Nación, se despejan los horizontes y se abren todos los veneros de riqueza atrayendo al país los hombres industriosos que transformarán el suelo agreste en praderas cultivadas (1885: 114).

La idea de civilización / barbarie se construye como un mito fundador y, como tal, se enseña a los niños en las escuelas. Roca se presenta como el héroe de la épica europea que las nuevas generaciones deben admirar.

\section{Molina Campos}

Sus obras pictóricas presentan dos características principales: por una parte, deben considerarse los entornos detallados en los que se lleva a cabo la acción; Por otro lado los personajes que se desarrollan dentro de ese entorno. Los gauchos, la China, los pulperos, los mulatos, los perros y los caballos, todos ellos arquetipos de la vida y la tradición del gaucho, poseen la fisonomía de un personaje de dibujos animados. Sus caras feroces con bocas enormes, sus ojos saltones y posturas exageradas, los hacen sobresalir sobre el campo.

Al representar la vida del gaucho, sus pinturas representan la explotación del ganado en casi todos los aspectos descritos. Como fuerza de trabajo: 


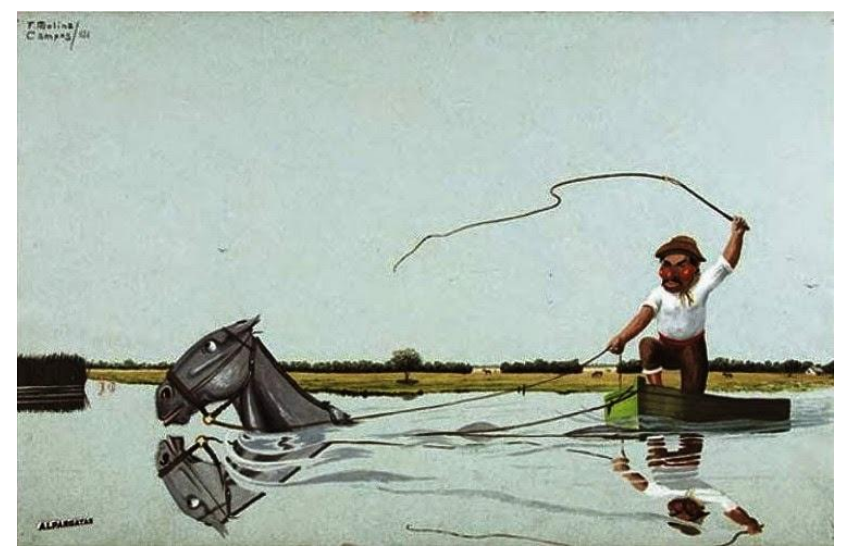

Figura 1. Molina Campos

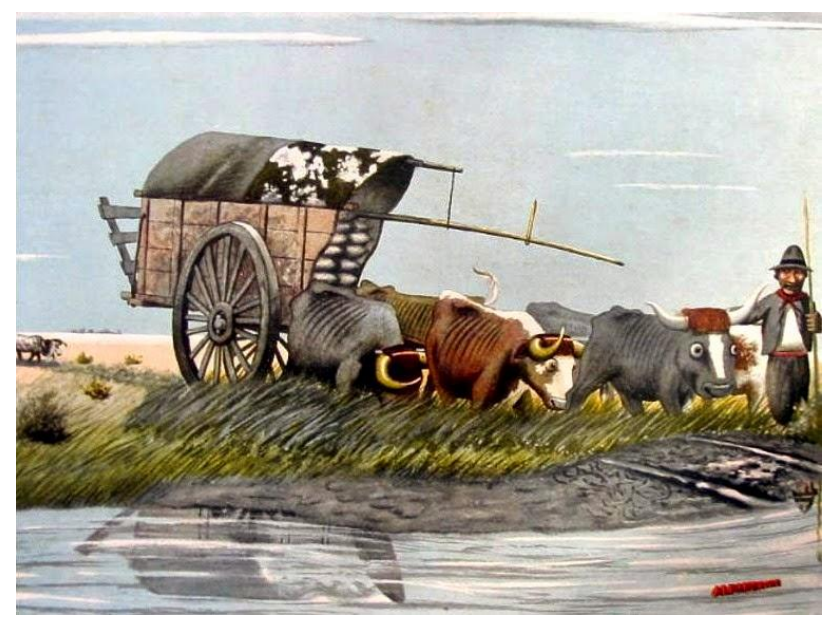

Figura 2. Molina Campos

\section{Como entretenimiento}

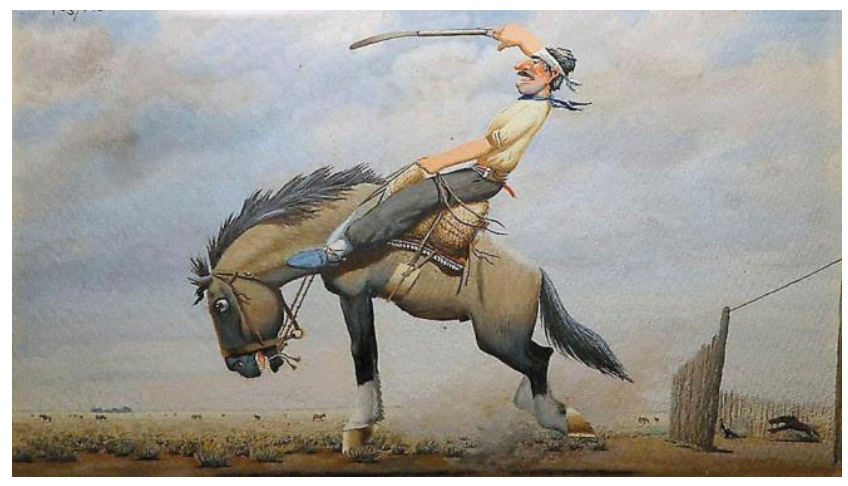

Question, Vol. 1, N. ${ }^{\circ}$ 64, octubre-diciembre 2019. ISSN 1669-6581

Instituto de Investigaciones en Comunicación | Facultad de Periodismo y Comunicación Social | Universidad Nacional de La Plata La Plata | Buenos Aires | Argentina 
Figura 3. Molina Campos

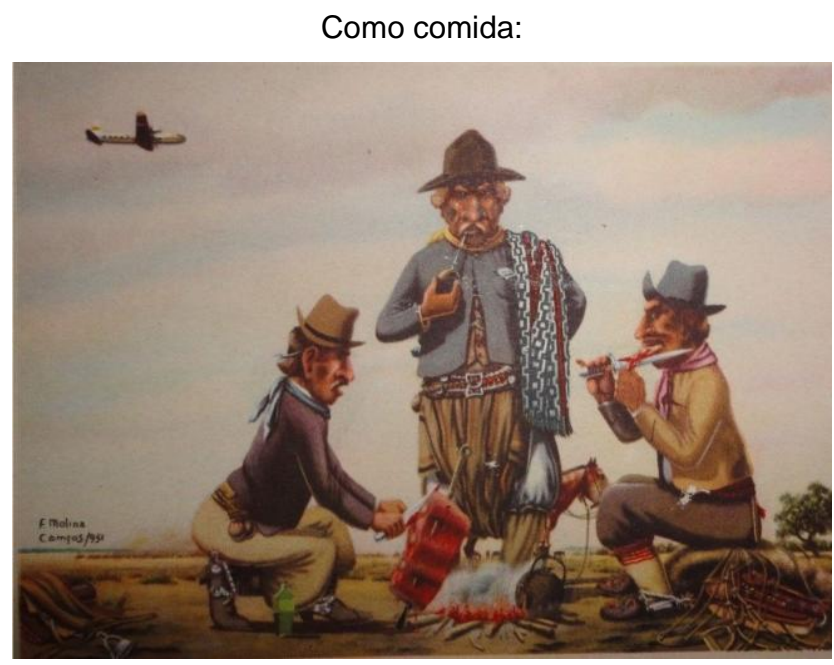

Figura 4. Molina Campos

De acuerdo con la propuesta de Kress \& van Leeuwen (2006), en el análisis de la función Ideacional se evidencia a los actores humanos involucrados en procesos transactivos materiales, es decir, procesos accionales que tienen un efecto en un animal no humano. En las figuras 1 y 3 , la agencia humana se ejerce sobre los animales de forma violenta: golpear y tirar de una cuerda para dominar y controlar. En la figura 2, aunque no parezca violento aún implica dominación, los animales son mano de obra guiados por un actor humano. Según estos autores podemos decir que hay dos agentes: el Gaucho realiza un proceso en el animal que a su vez lleva a cabo otro proceso: empujar, saltar, etc. En la figura 4 el proceso involucrado se puede considerar de dos maneras diferentes:

A. No transactivo: los gauchos se alimentan a sí mismos y este proceso no involucra a un segundo participante. Desde esta perspectiva la imagen muestra a personas comiendo y tomando mate. Esta escena representa la idea de reunión y amistad que el asado tiene en las tradiciones argentinas. Y esta escena tradicional del país es traída a los tiempos modernos con el avión en el lado superior izquierdo de la imagen.

B. Transactivo: los gauchos están comiendo una vaca, antes un ser vivo; por lo tanto, un proceso previo de matanza tuvo lugar antes de la comida. Esta interpretación rompe el escenario tradicional para dar lugar a una nueva visión sobre asuntos históricos. Las circunstancias en todas las imágenes representan también una situación tradicional en la Pampa: viajes, doma y asado. Todo en campos abiertos. 
Respecto a la función interpersonal (Kress y van Leeuwen, 2006: 42), las cinco imágenes invocan elementos realistas. Las personas y los animales representados presentan dimensiones más o menos proporcionadas y las acciones desarrolladas en las imágenes tienen una relación cercana con la forma en que se desarrollan en el mundo real. Las características de la cara son demasiado exageradas, una marca personal de Molina Campos como pintor pero no modifican el realismo de las imágenes. Los participantes no miran fuera de la imagen, como en una demanda (2006: 120); Se ofrece información: los participantes interactúan entre sí. Las imágenes muestran las escenas en un ángulo horizontal, una vez más, representan una escena verosímil, en relación con la realidad, y en una situación de paridad e igualdad con el espectador. No hay disputa entre lo que se ve y el espectador: el poder relativo se distribuye de manera uniforme.

La función textual también presenta una perspectiva muy realista: el centro de la imagen rige la interpretación: la información más importante está ahí. El sistema dado / nuevo permanece estable en las cinco imágenes. Lo que se da es la pampa, lo nuevo es siempre la situación. Como dijimos antes, estos procesos representan situaciones tradicionales en la Pampa. Las costumbres se presentan una vez más como el Espíritu Nacional, un elemento tradicional. Con Molina Campos, la representación masiva supera el nivel lingüístico para alcanzar el de la imagen. Los recursos multimodales están también configurados en torno a la construcción de una perspectiva discursiva especista.

\section{Libro de lectura Aleteos}

En continuidad con lo presentado en el libro El Argentino, en el punto 4.3., el libro de escuela primaria Aleteos (1949) presenta al Ganado como "riqueza nacional":

\section{Riqueza ganadera}

Pace en nuestras pampas numeroso Ganado que constituye una inmensa fuente de riqueza nacional. ¿Son estos animales originarios de nuestro suelo o llegaron desde tierras lejanas? La primera tropilla de yeguas y caballos fue introducida por Don Pedro de Mendoza. Otros conquistadores trajeron más tarde ovejas y vacunos que, abandonados en los campos inmensos, se multiplicaron prodigiosamente. Los poseedores de grandes extensiones de campo limitaron después sus estancias y fue preciso señalar los animales para distinguirlos de los ajenos (Davel de Deambros, 1949: 102).

Esta riqueza ahora es propiedad privada y es necesario marcarla para reclamar la propiedad. Por lo tanto, son posesiones antes que la riqueza. El ganado constituye una fuente inmensa de 
riqueza nacional, es una construcción que se repite a lo largo de muchos textos, como hemos visto. El concepto de Multiplicado prodigiosamente activa el marco del héroe nuevamente. El tema del destino aparece en las narraciones sobre Roca y la conquista del desierto.

\section{Otros elementos de la cultura popular}

Esta relación entre las vacas, el campo y la tradición se manifiesta en diferentes prácticas sociales.

Toro y Pampa es el séptimo álbum de estudio de la banda de heavy metal Almafuerte, lanzado en 2006 por los sellos discográficos Dejesu y Tocka Discos. Su nombre busca una relación con los ideales nacionalistas de extrema derecha que la banda sostiene.

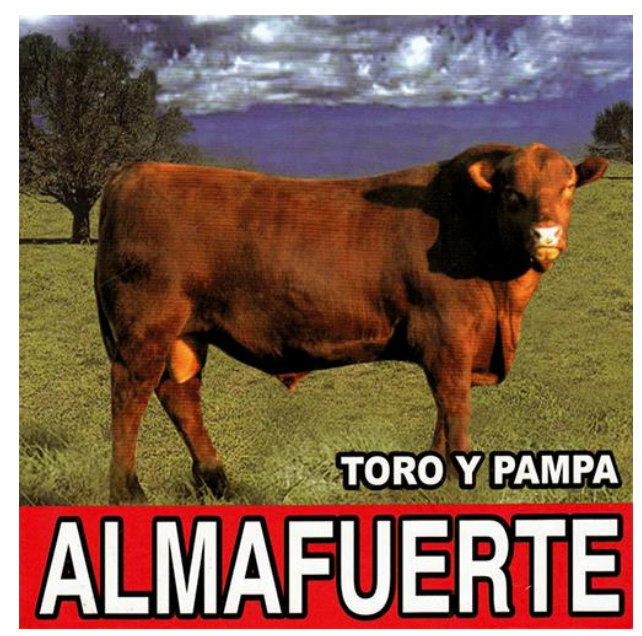

Figura 5. Almafuerte. Portada del disco Toro y Pampa

En esta imagen, el toro está mirando al espectador, está pidiendo compromiso con la imagen, no solo ofreciendo información. Como símbolo de la masculinidad hegemónica, el toro está asociado a los valores tradicionales a través de los campos en los que se encuentra. La masculinidad heterosexual está incluida tanto en la imagen del toro como en el significado general de asado, asociado con el "macho" argentino. Una vez más, el animal está involucrado en un proceso simbólico relacional, pero esta vez el toro representa lo tradicional nacional, no solo por lo que es, sino también porque está donde está; tan tradicional como se puede en Argentina: un toro en la Pampa.

Estos significados también se manifiestan en la imagen 6 a continuación. 


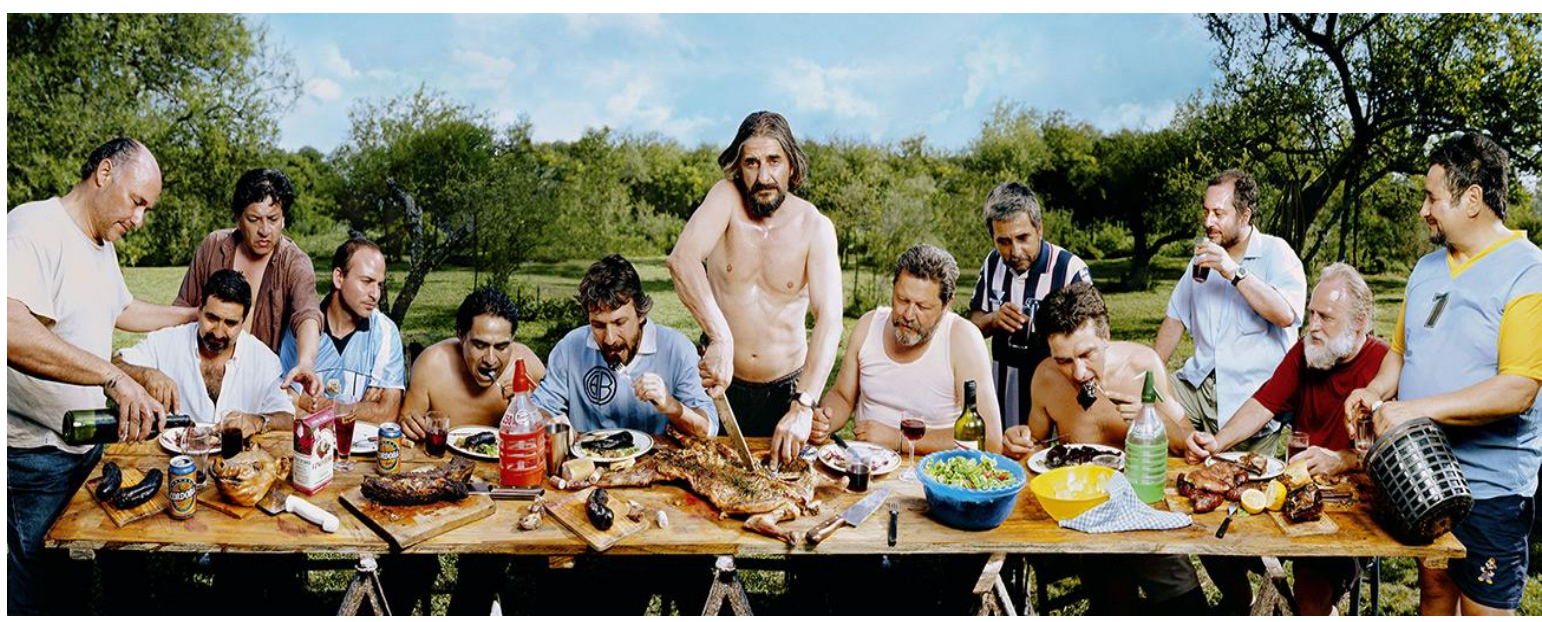

Figura 6. Marcos López. Asado en Mendiolaza, Córdoba

En este caso, la fotografía no solo retoma la última cena en clave de asado. Al hacerlo retoma los valores de masculinidad hegemónica y dogma de la imagen original, sumándole la idea de "tradición", la cual queda, de esta forma, asociada al concepto de "religión", en el sentido de costumbre regidora, de "historia a través de la cual se vive". Pero además, la fotografía de López agrega un factor importante, no presente en el cuadro de Leonardo Da Vinci: la demanda hacia el espectador. En la imagen original, Jesús mira hacia la mesa, con su mano izquierda extendida, palma hacia arriba, con dirección a los alimentos. En este caso, el personaje que ocupa la posición central en la imagen mira hacia la cámara, hacia el espectador de la imagen, demandando algún tipo de involucramiento con lo que ocurre en la imagen (Kress y van Leeuwen, 2006: 120). En el caso de la obra de Da Vinci, la imagen estaría ofreciendo información sobre la escena en la cual Jesús les comunica a sus discípulos que uno de ellos lo traicionará, es decir, es la representación de un conflicto. López, en cambio, intenta construir una escena de comunión y relajación: el asado argentino. Lo que su personaje principal parecería estar haciendo es solicitar el involucramiento del espectador para con esta situación, buscando generar empatía.

Discursos emergentes: voicot y transfeminismo antiespecista

La historia de la carne es el discurso dominante en Argentina al momento de escritura de este trabajo. Es la interpretación más difundida del signo vaca y por ende la que socialmente se impone como versión oficial (Raiter, 2003: 98). Pero existen otras historias, otros marcos, que interpretan este signo no en base a su utilidad. De acuerdo con Lakoff,(2004: 6) negar un 
marco solo refuerza su significado. Para salir de un significado dominante, debemos cambiar de marco, es decir, entrar en un marco en el que las interpretaciones dominantes de los signos no estén presentes. Por ejemplo, dentro de La Historia de la Carne, los animales denominados de cría son considerados ganado, alimento, y jamás se les otorgaría el status de persona. En la imagen 7 vemos como la ONG Voicot sale del marco dominante al presentar la representación de un cerdo junto con la palabra persona, presentando una nueva interpretación del signo "cerdo".

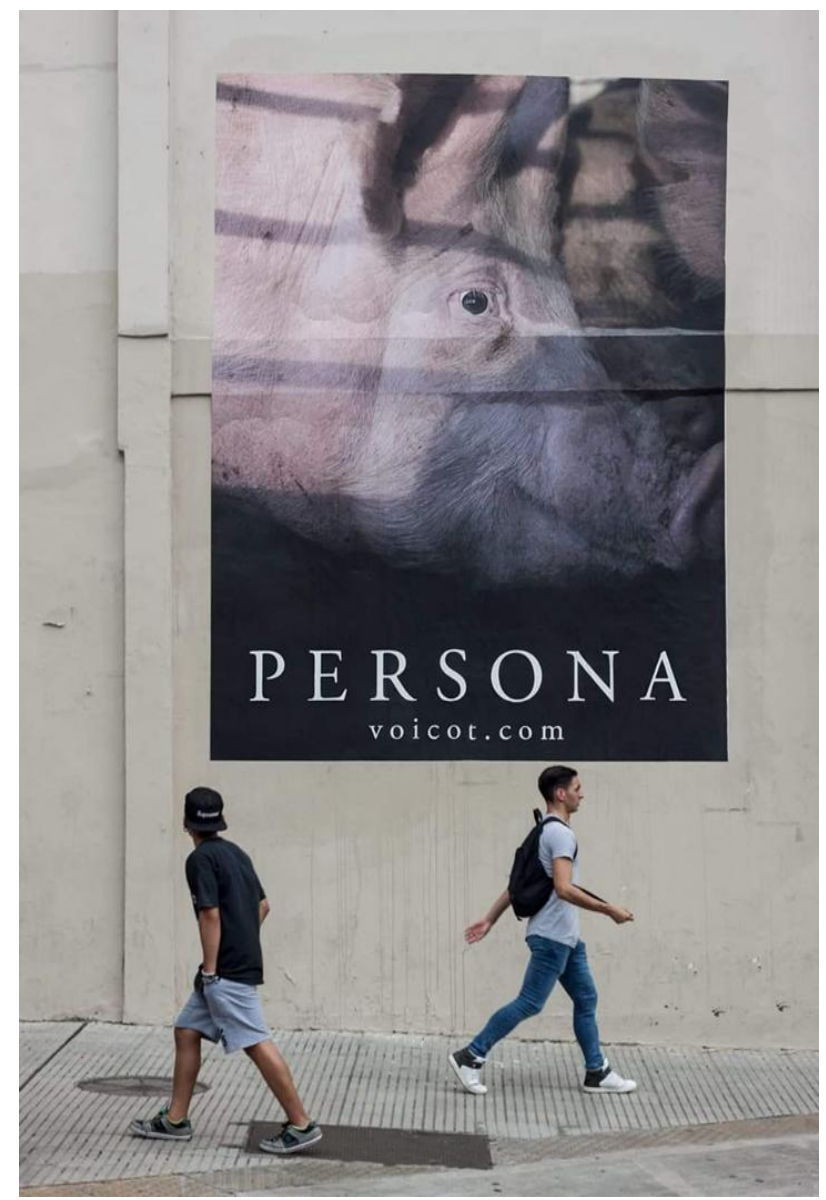

Figura 7. Voicot

Raiter (2003) denomina a estos discursos que presentan interpretaciones alternativas a las hegemónicas, siguiendo a Giménez Montiel, discursos emergentes: presentan significados propios que no son los que los marcos hegemónicos plantean.

De forma similar a Voicot, el movimiento llamado Transfeminismo Antiespecista propone signos propios que rompen las interpretaciones hegemónicas de la historia de la carne. 


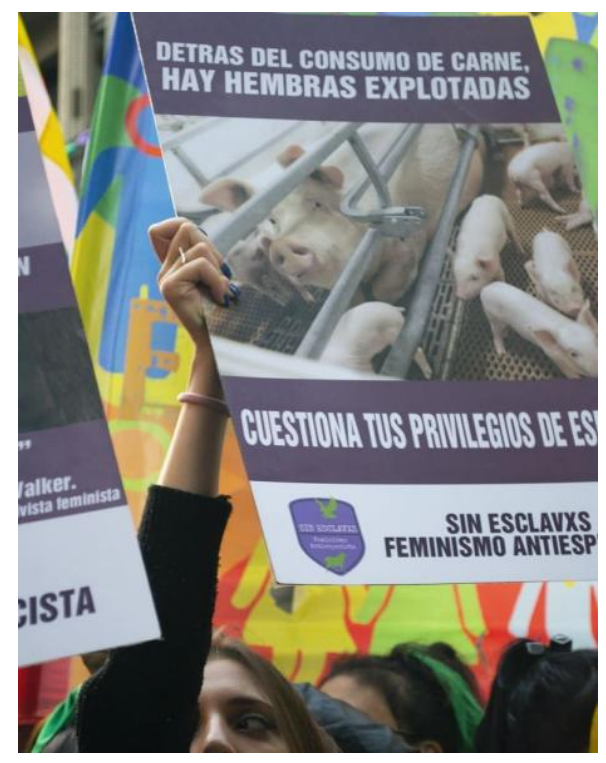

Figura 8. Transfeminismo Antiespecista

En este caso persiste parte del especismo discursivo, a través del término hembras, utilizado comúnmente para referirse a animales no humanos, pero aquí está asociado a otro término que se refiere, por lo general a individuos con el rasgo [+humano]: explotación.

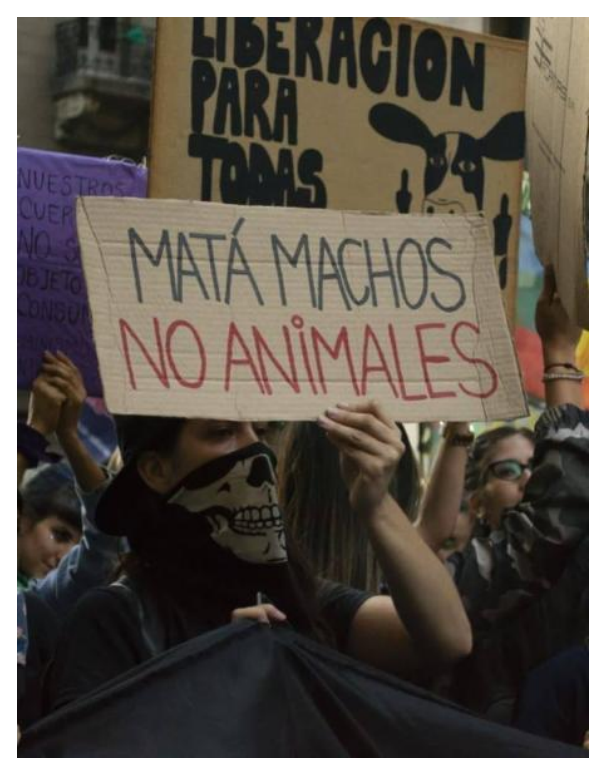

Figura 9. Transfeminismo Antiespecista 
En el caso de la imagen 9, es de interés el cartel que se muestra en segundo plano, con la leyenda "liberación para todas". Este "todas" inclusivo se refiere a todos los individuos con el rasgo [+femenino] sin discriminación por especie.

Tanto Voicot como Transfeminismo Antiespecista plantean interpretaciones nuevas, diferentes de las impuestas por el discurso dominante. Por eso los denominamos como parte de un discurso emergente sobre los animales no humanos.

\section{Conclusiones}

En términos de discurso identitario nacional, la ruptura de las Provincias Unidas del Río de la Plata con la corona española significó no solamente una separación económica, militar, etc. sino, sobre todo, una ruptura discursiva. Al cesar las operaciones comerciales y la comunicación con España cesan también los discursos provenientes de la península, por lo que los criollos, para fundar su nación, deben fundar un discurso nacional. De esta forma, el desierto es el símbolo del inicio, del vacío discursivo, de lo incivilizado: de la barbarie.

Los animales de cría se vuelven, en este contexto, un elemento civilizador en tanto permitió el establecimiento de población en zonas remotas. A partir de allí, el ganado mayormente bovino recorrió un largo trayecto para convertirse en emblema nacional, construyendo significados que atraviesan los discursos a través de los que interactuamos diariamente y que se manifiestan en prácticas sociales de todo tipo.

Estos discursos plantean prácticas sociales que no solo son destructivas para con animales no humanos sino también para con el entorno en el que tanto humanos como no humanos vivimos. Sin embargo existen también discursos que proponen signos diferentes y prácticas sociales diferentes, evitando las destructivas y tendiendo hacia una visión no dañina de formas de vida no humanas. La propuesta de la Ecolingüística como disciplina tiene como objeto deconstruir los discursos y marcos dañinos para colaborar en la construcción de discursos y marcos que posibiliten prácticas sociales alternas. En este sentido, la deconstrucción del discurso identitario nacional, la Historia de la Carne, es una tarea obligatoria que involucra el trabajo de diferentes disciplinas. En tiempos de cambio como los actuales, comienza a hacerse evidente que las prácticas dañinas hegemónicas se ejercen sobre numerosos colectivos, por lo cual las deconstrucciones que contemplan los diferentes tipos de subalternidad parecen ser los más efectivos en sus objetivos renovadores. Al momento este parece ser el único camino real hacia la igualdad. 
Notas

(1) Uno de los principales resultados en las ciencias cognitivas y del cerebro es que pensamos en términos de estructuras típicamente inconscientes llamadas "marcos" (a veces "esquemas"). Los marcos incluyen roles semánticos, relaciones entre roles y relaciones con otros marcos. Un marco hospitalario, por ejemplo, incluye los roles: médico, enfermera, asistente, visitante, recepcionista, sala de operaciones, sala de recuperación, bisturí, etc. Entre las relaciones se encuentran las especificaciones de lo que sucede en un hospital, por ejemplo, los médicos operan a pacientes en Salas de operaciones con escalpelos. Estas estructuras se realizan físicamente en circuitos neuronales en el cerebro. Todo nuestro conocimiento utiliza marcos, y cada palabra se define a través de los marcos que neurológicamente activa. Todo pensamiento y conversación implica "encuadre". Y como los marcos vienen en sistemas, una sola palabra normalmente activa no solo su marco de definición, sino también gran parte del sistema en el que se encuentra el marco de definición (Traducción del autor).

(2) Son patrones imaginativos, redes de símbolos poderosos que sugieren formas particulares de interpretar el mundo. Ellos le dan forma a su significado. Por ejemplo, las imágenes de la máquina, que comenzaron a impregnar nuestro pensamiento en el siglo xvn, todavía son potentes. Todavía solemos vernos a nosotros mismos, y a los seres vivos que nos rodean, como piezas de un reloj: elementos del tipo que nosotros mismos podemos hacer, y podríamos decidir rehacerlos si nos conviene más. De ahí el lenguaje seguro de "ingeniería genética" y "los componentes básicos de la vida" (Traducción del autor).

(3) El papel del lenguaje en la estructuración de las relaciones de poder, en particular, ha sido objeto de un minucioso análisis (...) La mayor parte de este trabajo sobre el lenguaje y el poder se centra en el papel del discurso en la opresión y la explotación. Por ejemplo, la revista Discourse and Society está dedicada al "poder, el dominio y la desigualdad, y al papel del discurso en su legitimación y reproducción en la sociedad, por ejemplo, en los dominios de género, raza, etnia, clase o religión mundial". Sin embargo, con raras excepciones, el papel del discurso en la dominación por parte de los humanos de otras especies se ha descuidado casi por completo en el campo del análisis crítico del discurso. Se habla de poder como si fuera una relación entre personas solamente; por ejemplo, Fairclough (1992) describe la manera en que "el lenguaje contribuye a la dominación de algunas personas por otras" ... Debido a las raíces neomarxistas del análisis del discurso crítico, el análisis se centra en la hegemonía, donde la opresión de un grupo se lleva a cabo ideológicamente. Más que coercitivamente, a través de la fabricación del consentimiento. En el caso de los animales, el poder es coercitivo, llevado a cabo por un pequeño número de personas involucradas en organizaciones que cultivan y 
utilizan animales. Los animales no aceptan su tratamiento debido a una aceptación acrítica de la ideología del opresor, y no se les puede otorgar poder para resistir los discursos que los oprimen. (Traducción del autor):

(4) La historia de la carne sigue la estructura narrativa de la narración. Alice B. Toklas implica esto en su libro de cocina cuando, en un capítulo titulado "Asesinato en la cocina", utiliza el estilo de una historia de detectives para describir cómo matar y cocinar animales. $25 \mathrm{~A}$ través de recetas, ella proporciona la conclusión apropiada a la muerte de los animales de acuerdo con los textos de carne; el animal se vuelve delicioso, comestible... Comer carne es una historia que se aplica a los animales, da sentido a la existencia de los animales... La historia de la carne sigue una tipología sagrada: el nacimiento de un dios, el desmembramiento del cuerpo del dios y la Resurrección. Esta historia sagrada allana el camino para una acción mundana del significado de desmembramiento y resurrección: se logra a través del consumo de carne. (Traducción del autor).

\section{Bibliografía}

Adams, C. (2017)[1990]. The Sexual Politics of Meat. A feminist-vegetarian critical theory. New York: Bloomsbury.

Alberdi, J. B. (2017)[1852]. Bases y puntos de partida para la organización política de la República Argentina. Buenos Aires: Biblioteca del Congreso de la Nación.

Althusser, L. (1971). Lenin and Philosophy and other Essays. Harlow: Longman Group Limited.

Andrews, J. (1827). Journey from Buenos Aires, through the provinces of Cordova, Tucuman, and Salta, to Potosí. London, John Murray.

Beaumnt, J. (1828). Travels in Buenos Aires, and the Adjacent Provinces of The River of La Plata with observations. London: James Ridgway.

Berger, P. y Luckmann, T. (2003) [1968]. La construcción social de la realidad. Buenos Aires: Amorrortu.

Bond Head, F. (1826). Rough Notes taken during some rapid journeys across the Pampas and among the Andes. London: John Murray.

Caldcleugh, A. (1825). Travels in South America During the Years 1819-20-21. London: John Murray.

Davel de Deambros, R. (1949). Aleteos. Segundo libro de lectura. Buenos Ares: Ángel Estrada y Cía. Editores. .

Echeverría, E. (1870). La cautiva. Buenos Aires: Imprenta y Librería de Mayo.

Echeverría, E. (1872). El matadero. Buenos Aires: Imprenta y Librería de Mayo. 
Hadas, M. (1948). Aeneas and the tradition of national hero. The American Journal of Philology, Vol. 69. No. 4, pp. 408-414.

Hart, C. (2014). Discourse, Grammar and Ideology. London: Bloomsbury

Kress, G. \& van Leeuwen, T. (2006). Reading Images: the grammar of visual design. London: Routledge.

Lakoff, G. (2010). Why it matters how we frame the environment. En Environmental Communication, $4 ; 1,70-81$.

Lakoff, G. (2014) [2004] Don't think of an elephant! Know Your Values and Frame the Debate. Vermont: Chelsea Green Publishing.

Midgley, M. (2003). Myths We Live By. London: Routledge.

Miers, J. (1826). Travels in Chile and La Plata. London: Baldwin.

Navarro, A. (2016. Representaciones e identidades del discurso especista: el caso de la carne vacuna y sus derivados en la Argentina (2000-2012). Tesis de Doctorado. Defendida en Marzo. Facultad de Periodismo y Comunicación Social, Universidad Nacional de La Plata.

Pelliza, M. (1885). El Argentino. Texto de lectura. Buenos Aires: Igon Hermanos, Editores.

Prieto, A. (1996). Los viajeros ingleses y la emergencia de la literatura argentina, 1820-1850. Buenos Aires: Editorial Sudamericana.

Raiter, A. (2003). Lenguaje y sentido común. Buenos Aires: Biblos.

Sarmiento, Domingo, F. (1993)[1845]. Facundo o Civilización y barbarie. Introducción de Carlos Altamirano. Bs. As., Espasa Calpe - Colección Austral.

Stibbe, A. (2015). Ecolinguistics: Language, Ecology and the Stories We Live By. London: Routledge.

Stibbe, A. (2001). Language, power and the social construction of animals. En: Society \& Animals, Volume 9: Issue 2.

van Dijk, T. (1999). El análisis crítico del discurso. En: Anthropos (Barcelona), 186, septiembreoctubre, pp. 23-36.

Whorf, B. L. (1956). Language, Thought, and Reality. Cambridge, Massachusetts: Technology Press of Massachusetts Institute of Technology.

Imágenes

Figura 1. Molina Campos. Sin nombre. Recuperado de https://museolaslilas.org/SalaMolinaCampos.php [Acceso: 18/07/2019] 
Figura 2. Molina Campos. Sin nombre. Recuperado de https://museolaslilas.org/SalaMolinaCampos.php [Acceso: 18/07/2019]

Figura 3. Molina Campos. Aplicau a beyaquiar. Recuperado de https://museolaslilas.org/SalaMolinaCampos.php [Acceso: 18/07/2019]

Figura 4. Molina Campos. Sin nombre. Recuperado de https://museolaslilas.org/Sala-

MolinaCampos.php [Acceso: 18/07/2019]

Figura 5. Almafuerte. Toro y pampa. Buenos Aires: Toka discos.

Figura 6: Asado en Mendiolaza, Córdoba, 2001. Marcos López. Recuperado de https://www.museoreinasofia.es/en/collection/artwork/asado-mendiolaza-roasted-meatmendiolaza [acceso: 18/07/2019].

Figura 7. Voicot. Persona. Recuperado de https://cdni.rt.com/actualidad/public images/2018.11/original/5bf70855e9180fc1728b45 67.jpg

[Acceso: 18/07/2019]

Figura 8. Transfeminismo Antiespecista. Recuperado de https://www.google.com/url?sa=i\&rct=i\&q=\&esrc=s\&source=images\&cd=\&cad=ria\&uact =8\&ved=2ahUKEwjU8ub9kb jAhXiHLkGHRwgAl8Qjhx6BAgBEAM\&url=https\%3A\%2F \%2Fwww.facebook.com\%2Fsinesclavxs\%2F\&psig=AOvVaw0w67KWM5WO8qkMtZrOG2k\&ust=1563562354995436 [Acceso: 18/07/2019]

Figura 9. Transfeminismo Antiespecista. Recuperado de https://www.google.com/url?sa=i\&rct=i\&q=\&esrc=s\&source=images\&cd=\&cad=rja\&uact =8\&ved=2ahUKEwjU8ub9kb iAhXiHLkGHRwgAl8Qjhx6BAgBEAM\&url=https\%3A\%2F \%2Fwww.facebook.com\%2Fsinesclavxs\%2F\&psig=AOvVaw0w67KWM5WO8qkMtZrOG2k\&ust=1563562354995436 [Acceso: 18/07/2019] 